\title{
Long-term exposure to low-dose Haemophilus influenzae during allergic airway disease drives a steroid-resistant neutrophilic inflammation and promotes airway remodeling
}

\author{
Xu Yang ${ }^{1}$, Yijie Wang ${ }^{1,2}$, Shengtao Zhao ${ }^{1,3}$, Ran Wang ${ }^{1}$ and Changzheng Wang ${ }^{1}$ \\ ${ }^{1}$ Institute of Respiratory Disease, Xinqiao Hospital, Third Military Medical University (Army Medical University), Chongqing, \\ 400037, China \\ ${ }^{2}$ Department of Respiratory Medicine, The 305 Hospital of PLA, Beijing, 100017, China \\ ${ }^{3}$ Department of Respiratory Medicine, Kunming General Hospital of Chengdu Military Region, Kunming, 650032, China \\ Correspondence to: Changzheng Wang, email: czwang@netease.com \\ Keywords: allergic airway disease; Haemophilus influenzae; neutrophilic inflammation; airway remodeling; long-term effect; \\ Immunology \\ Received: December 21, $2017 \quad$ Accepted: January 14, $2018 \quad$ Published: May 18, 2018 \\ Copyright: Yang et al. This is an open-access article distributed under the terms of the Creative Commons Attribution License 3.0 \\ (CC BY 3.0), which permits unrestricted use, distribution, and reproduction in any medium, provided the original author and source \\ are credited.
}

\section{ABSTRACT}

Growing evidences indicate that bacteria are associated with pathogenesis of neutrophilic asthma. However, the long-term effect of airway bacterial colonization remains unclear. We sought to establish a murine model to simulate the airway inflammation of long-term bacterial colonization, and to assess the effects of bacteria on allergic airway disease (AAD). BALB/c mice were sensitized twice and subsequently challenged with ovalbumin (OVA) and exposed to low-dose Haemophilus influenzae for approximately $\mathbf{2}$ months. Mice in treatment groups inhaled budesonide for consecutively 6 days in the last week. Airway inflammatory phenotype, immune response, phagocytic capacity, mucus production, airway remodeling and steroid sensitivity were assessed. Long-term exposure to low-dose $H$. influenzae during AAD did not cause serious infection but only a slightly increased airway inflammation, which resembled the colonization. Inflammatory phenotype was converted from a steroid-sensitive T helper (Th) 2-associated eosinophilic inflammation to a steroidresistant Th17-associated neutrophilic inflammation. The increased neutrophilic inflammation was accompanied by defects in regulatory $T$ cell (Treg)-associated immunosuppression and macrophage phagocytosis, and finally promoted mucus hypersecretion and airway remodeling. These features resembled those of refractory neutrophilic asthma in humans. These findings indicate that in asthmatic patients, airway bacterial colonization may be a potential therapeutic target. Minimizing the pathogen burden in airway, such as Haemophilus influenzae, may be beneficial.

\section{INTRODUCTION}

Asthma is now recognized as a chronic heterogeneous airway inflammatory disease. Although Th2-derived eosinophilic inflammation is the hallmark of asthma, a typical eosinophilic inflammation is found absent in nearly $50 \%$ of asthmatics [1]. Neutrophilic asthma is a subgroup of non-eosinophilic asthma [2], and is characterized by an intense increase in airway neutrophils, severe disease conditions [3], airflow limitations [4], and poor response to steroid treatments [5]. These severe and treatment-resistant cases of asthma bring a heavy financial burden, thus better understanding of the pathogenesis and novel therapies are needed.

Recent years, with the development of cultureindependent molecular technology, the lower airway is no longer thought sterile [6]. Although asthma is usually known as a non-infectious allergic disease, a growing 
number of evidences have linked it to microbes. Compared with healthy controls, patients with asthma have greater airway bacterial burdens [7]. And the burdens present even higher in asthmatics with lower levels of Th2-related airway inflammation [8]. Furthermore, the airway bacterial community composition, which has been demonstrated different between healthy controls and asthmatic patients [9], varies with disease features, steroid responses and inflammatory phenotypes of asthma $[8,10,11]$. About $60 \%$ of patients with neutrophilic asthma have pathogenic microorganisms cultured from their bronchoalveolar lavage fluids (BALF)[12]. Detection of bacteria in the lower airways is associated with acute wheezy episodes [13], enhanced neutrophilic airway inflammation [14], and impaired pulmonary function [15], which can be improved by antibiotics treatment [16]. These findings suggest that bacterial colonization in the airway in asthma is much more common than it was expected and probably plays a role in pathogenesis of neutrophilic asthma.

The effects of bacteria can be dose and species dependent $[17,18]$. Although transient bacterial infection has been reported to be able to induce a steroid-resistant chronic neutrophilic inflammation in a period of time [19], whether and how a long-term colonization of bacteria with a low dose in the airway would affect the progression of asthma is yet unknown.

Unlike infection, airway bacterial colonization is often subclinical and free of exaggerated symptoms. And bacterial burdens in the airway can be variable over time, even in a same person. The two factors both make it difficult to identify a group of patients who have long-term colonization by enough loads of bacteria, thus characteristics of these patients is hard to be determined. On the other hand, ethical issues won't allow direct administration of certain bacterial species to humans to investigate their influences on AAD on mechanism level. Therefore, studies of this kind must be done using animal models.

The aim of the present study was to establish a murine model to simulate the slight inflammation of longterm airway bacterial colonization, and investigate the long-term effects of bacterial exposure on OVA-induced AAD, to elucidate the potential association between bacterial colonization and features of neutrophilic asthma. Haemophilus influenzae, the predominant pathogen involved in neutrophilic asthma [20] and associated with significantly higher levels of airway inflammation than other common pathogens [21], was applied in the study.

\section{RESULTS}

\section{Transient exposure to $H$. influenzae}

In the present study, we first sought to determine the effects of transient exposure to $H$. influenzae and find an appropriate dose for $H$. influenzae, to establish a further long-term model without serious infection. For this, nonallergic mice were intranasally inoculated with a series doses of $H$. influenzae, from $1 \times 10^{5}$ to $1 \times 10^{8}$ colonyforming units (CFU).

Whatever the dose was, all mice inoculated were survived. However, symptoms were different among groups. Mice exposed to $10^{8} \mathrm{CFU}$ showed a serious piloerection and rigor, and were in a hunched posture. Those exposed to $10^{7} \mathrm{CFU}$ showed a mild piloerection and a lack of grooming. In comparison, mice in $10^{6}$ and $10^{5}$ CFU groups had no obvious symptoms.

There was a direct correlation between bacterial dose and weight loss. Body weight dropped to the lowest level at day 2 postinfection. As expected, mice in $10^{8}$ CFU group had the most significant weight loss, but by lowering the bacterial CFU constant, the weight loss decreased. At day 7 postinfection, weights of almost all mice returned to the level of baseline (Figure 1A).

There were no detectable viable $H$. influenzae in the BALF of mice receiving the dose of $10^{5} \mathrm{CFU}$, even if at the first day postinfection. In comparison, more than $70 \%$ of mice in another three groups recovered $H$. influenzae from BALF at day 1 postinfection. Mice in $10^{8} \mathrm{CFU}$ group recovered much greater numbers of $H$. influenzae than those in $10^{7}$ and $10^{6} \mathrm{CFU}$ group (Figure 1B). However, at days 2, 4 and 7 postinfection, whatever the dose of $H$. influenzae inoculated was, the proportions of mice with bacterial viable detection were less than $20 \%$. The highest proportion, which was $40 \%$ and correlated with a mean recovery number of $10^{1.15} \mathrm{CFU} / \mathrm{ml}$ in the BALF, occurred at day 7 postinfection in $1 \times 10^{6} \mathrm{CFU}$ group.

H. influenzae of $10^{8}$ and $10^{7} \mathrm{CFU}$ led a transient significant increases in BALF cell numbers. Total cell and neutrophil numbers peaked at day 1 postinfection, then declined to the levels around baseline at day 7 (Figure 1C, 1D); while macrophage number increased progressively and became higher at days 4 and 7 postinfection (Figure $1 \mathrm{E})$. Mice in $10^{6}$ and $10^{5} \mathrm{CFU}$ groups showed the same trends but not significant (Figure 1C-1E).

Following above observations, $1 \times 10^{6} \mathrm{CFU}$, which had viable recovery of $H$. influenzae but no obvious symptoms, weight loss and inflammatory cell increase, was chosen as the dose for further application.

\section{Long-term exposure to low-dose $\boldsymbol{H}$. influenzae combined with or without allergic airway disease does not cause serious infection}

To investigate the effects of long-term exposure to $H$. influenzae on $\mathrm{AAD}$, mice were intranasally inoculated with the selected dose of $H$. influenzae $(1 \times$ $\left.10^{6} \mathrm{CFU}\right) 24$ hours after the last OVA challenge every week. The effects were assessed after 8-week inoculation and 9-week challenges (Figure 2A). To better estimate the inflammatory response of long-term exposure to 
the selected dose of $H$. influenzae, we also set positive controls, in which mice were exposed to $1 \times 10^{7} \mathrm{CFU}$ of H. influenzae.

During the time from the first inoculation with 1 $\times 10^{6} \mathrm{CFU}$ of $H$. influenzae to the endpoint, allergic and non-allergic mice (OVA/Hi and Hi groups) both showed no significant changes in their body weights compared with mice that were not inoculated with bacteria (OVA and saline groups). In comparison, the 8-week exposure to $1 \times 10^{7} \mathrm{CFU}$ of $H$. influenzae resulted in significantly progressive weight decreases (Figure $2 \mathrm{~B}$ ).

Both allergic and non-allergic mice exposed to 1 $\times 10^{7} \mathrm{CFU}$ had more than $1500 \times 10^{4}$ cells $/ \mathrm{ml}$ of BALF, which were much higher than those exposed to 0 or 1 $\times 10^{6} \mathrm{CFU}$, which had lower than $300 \times 10^{4}$ cells $/ \mathrm{ml}$ of BALF (Figure 2C).

The histopathology of lungs showed similar trends. Mice in saline group showed no pathology. Mice with AAD (OVA group) had some inflammatory cells, including eosinophils, around the bronchioles. Compared with the corresponding controls, mice with long-term exposure to $1 \times 10^{6} \mathrm{CFU}$ of $H$. influenzae had a mild increased inflammation. However, infiltration of inflammatory cells was significantly aggravated by longterm exposure to $1 \times 10^{7} \mathrm{CFU}$ of $\mathrm{H}$. influenzae (both $\mathrm{Hi}$ and OVA/Hi groups) with apparent alveolar consolidation occurred (Figure 2D).

In addition, mice with long-term inoculation with $1 \times 10^{6} \mathrm{CFU}$ of $H$. influenzae had no symptoms. But
$28.3 \%$ of mice treated with $1 \times 10^{7} \mathrm{CFU}$ died from serious infection before endpoint.

These results suggested that long-term exposure to low-dose $\left(1 \times 10^{6} \mathrm{CFU}\right) H$. influenzae did not cause serious infections in both allergic and non-allergic mice, and successfully simulated the slight airway inflammation of bacterial colonization.

\section{Long-term exposure to low-dose $\boldsymbol{H}$. influenzae during allergic airway disease converts a steroid-sensitive Th2-associated eosinophilic inflammation to a steroid-resistant Th17- associated neutrophilic inflammation}

As described above, AAD was established and maintained by OVA sensitization twice and challenge three times a week. H. influenzae was administered by intranasally inoculation with $1 \times 10^{6} \mathrm{CFU}$ of $H$. influenzae once a week. To investigate the effects of steroid treatment, budesonide was given via inhalation once per day for 6 consecutive days just before endpoint. (Figure 3A).

Long-term exposure to low-dose $H$. influenzae significantly modified the airway inflammatory phenotype in mice with AAD. The induction of AAD (OVA group) resulted in airway eosinophilic inflammation, accompanied by an elevation in Gata3 (Th2 differentiation factor) mRNA expression in lung tissue and increases in interleukin (IL)-4 and IL-5 (Th2-associated cytokines) levels in BALF compared with saline controls (Figure
A

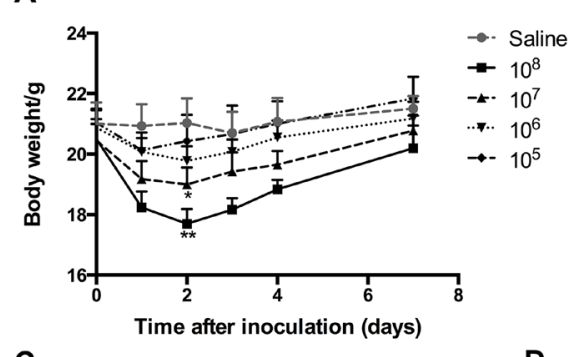

C

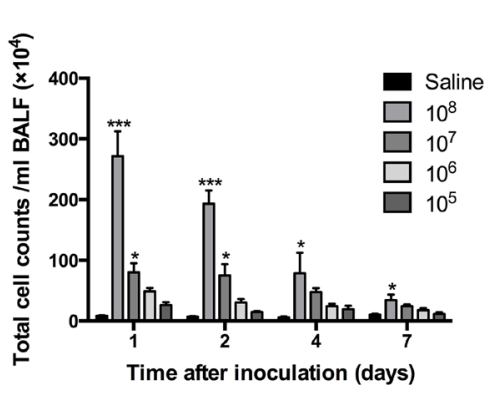

B

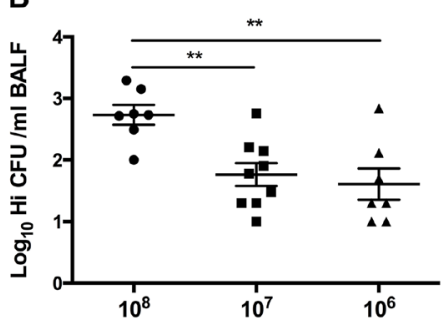

D

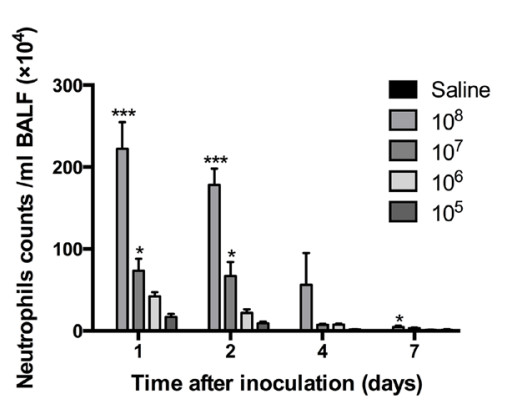

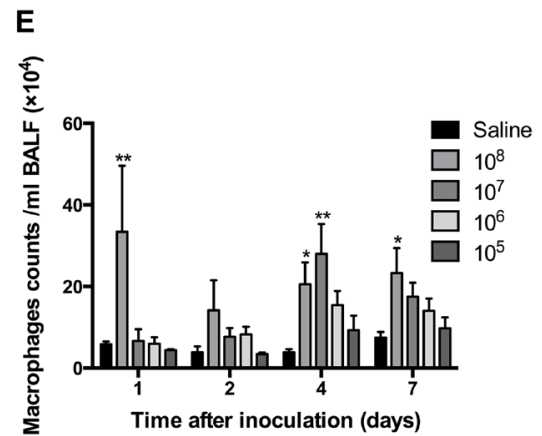

Figure 1: The effects of transient exposure to different doses of $\boldsymbol{H}$. influenzae. Mice were inoculated intranasally with $1 \times 10^{5}$ to $1 \times 10^{8} \mathrm{CFU}$ of $H$. influenzae or saline. The effects of different doses of $H$. influenzae on body weight changes (A), bacterial recovery from the BALF at day 1 postinfection (B), and numbers of total cell (C), neutrophil (D) and macrophage (E) in the BALF at days 1, 2, 4 and 7 postinfection were assessed. Data presented the mean \pm SEM. Significant differences between saline and inoculation groups or within the inoculation groups are shown as ${ }^{* * *} \mathrm{P}<0.001,{ }^{* *} \mathrm{P}<0.01,{ }^{*} \mathrm{P}<0.05$. Hi: Haemophilus influenzae. 
3B-3E). However, long-term exposure to $H$. influenzae during AAD (OVA/Hi group) significantly reduced the eosinophil number in BALF (Figure 3B). This reduction was accompanied by down-regulation in Gata3 mRNA expression in lung tissue (Figure 3C). Levels of IL-4 and IL-5, which were involved in eosinophil recruitment, were also significantly decreased in BALF of mice with AAD combined bacterial exposure compared with AAD alone (Figure 3D-3E).

In the meanwhile, the mild airway neutrophilic inflammation in AAD was significantly enhanced and became predominant when combined with long-term exposure to $H$. influenzae. Numbers of neutrophils in BALF were significantly increased in OVA/Hi group vs. OVA group and this increase was not shown in nonallergic mice exposed to $H$. influenzae alone (Figure 3F). In addition, compared with AAD alone, expression of Th17 differentiation factor, Ror $\gamma$, was significantly up regulated by bacterial exposure during AAD in lung tissue (Figure 3G). Mice exposed to $H$. influenzae during AAD also had an elevated level of IL-17 in BALF than those were not exposed (Figure $3 \mathrm{H}$ ). Keratinocyte chemokine (KC), which is the mouse ortholog of human IL-8 and can be induced by IL-17 to recruit neutrophils, also showed

A

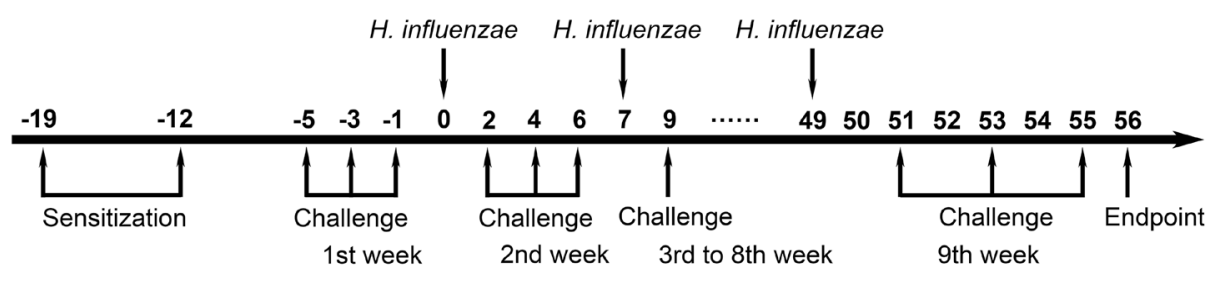

B

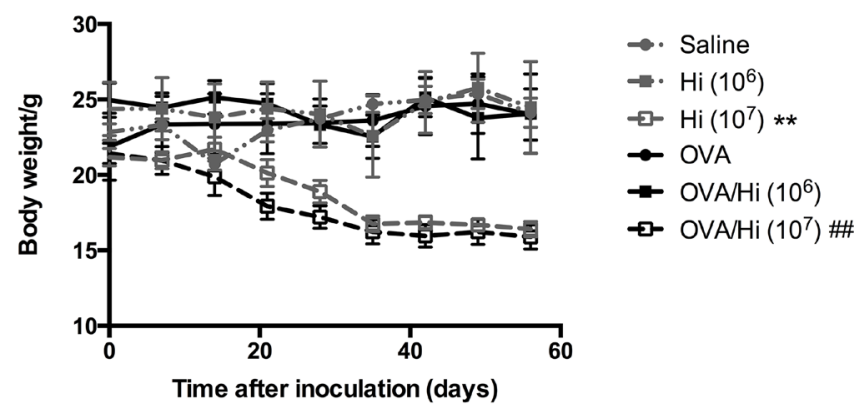

C

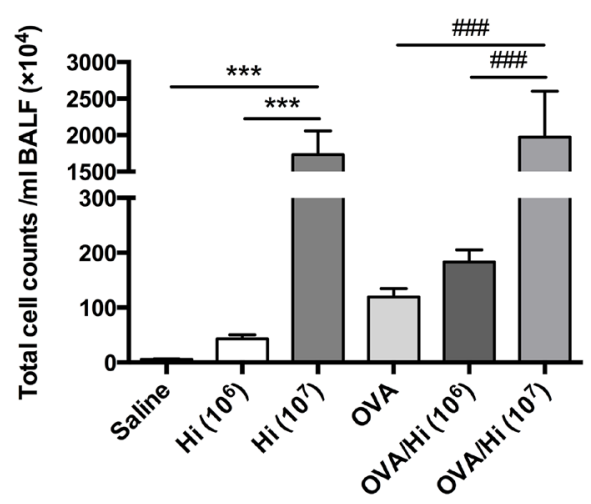

D

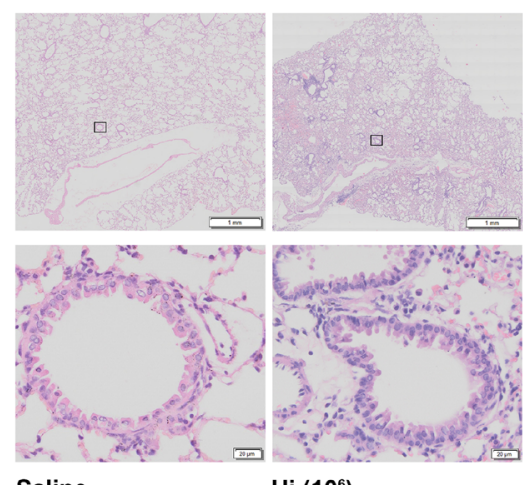

Saline

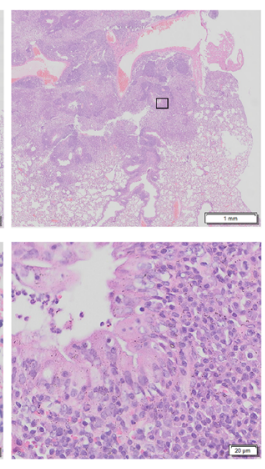

$\mathrm{Hi}\left(\mathbf{1 0}^{\mathrm{7}}\right)$

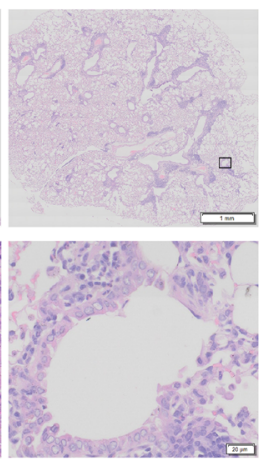

OVA

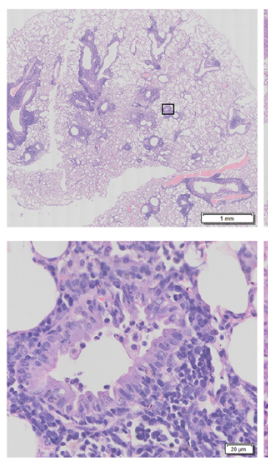

OVA/Hi $\left(10^{6}\right)$

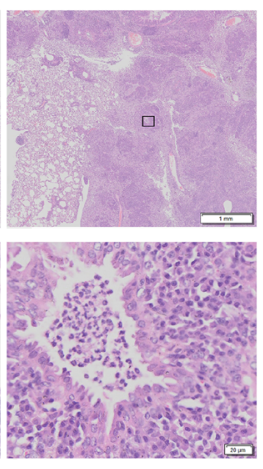

OVA/Hi $\left(10^{7}\right)$

Figure 2: Long-term exposure to low-dose $\boldsymbol{H}$. influenzae combined with or without allergic airway disease does not cause serious infection. Mice were sensitized twice (days -19 and -12) and challenged three times a week (day -5 to 55) with OVA to establish and maintain an allergic airway inflammation. Respectively, $1 \times 10^{6}$ (selected) and $1 \times 10^{7}$ (positive control) CFU of $H$. influenzae were administered 24 hours after the third challenge every week (day 0 to 49). Seven days after the 8th administration and 1 day after the last challenge (day 56), mice were sacrificed (A). To estimate the severity of infection, changes in body weights (B), total cell counts in the BALF $(\mathbf{C})$, and lung histopathology $(\mathbf{D}$, original magnification: upper, $\times 8$; lower, $\times 200)$ were assessed. Data presented the mean \pm SEM. Significant differences between groups without $\mathrm{AAD}$ are shown as ${ }^{* * *} \mathrm{P}<0.001,{ }^{* * *} \mathrm{P}<0.01$. Significant differences between groups with $\mathrm{AAD}$ are shown as ${ }^{\# \#} \mathrm{P}<0.001,{ }^{\#} \mathrm{P}<0.01$. For body weights change evaluation, $\mathrm{P}$ value was calculated by one-way repeated measures ANOVA and was for the entire time-related weight. Hi: Haemophilus influenzae. 
significant increase in the BALF of mice in OVA/Hi group compared with OVA group (Figure 3I).

After budesonide treatment, Th2-associated eosinophilic inflammation in mice with AAD alone (OVA/Bud group) was significant suppressed. In contrast, budesonide treatment did not cause reductions of all above key features of allergic airway inflammation in mice combined AAD with long-term exposure to $H$. influenzae (OVA/Hi/Bud group) (Figure 3B-3E).

Collectively, our results showed that long-term exposure to $H$. influenzae during AAD might convert the airway inflammation from a steroid-sensitive Th2 associated eosinophilic phenotype to a steroid-resistant
Th17 associated neutrophilic phenotype, which resembles the features of neutrophilic asthma in human.

\section{Long-term exposure to low-dose $\boldsymbol{H}$. influenzae during allergic airway disease inhibits Treg- associated immunosuppression but does not affect Th1-associated inflammation}

To determine whether long-term exposure to $H$. influenzae during AAD had effects on Tregs, expression of Foxp3, the Treg differentiation factor, and level of IL10, a key anti-inflammatory cytokine mainly produced by Tregs, were assayed. Compared with AAD alone, bacterial

A

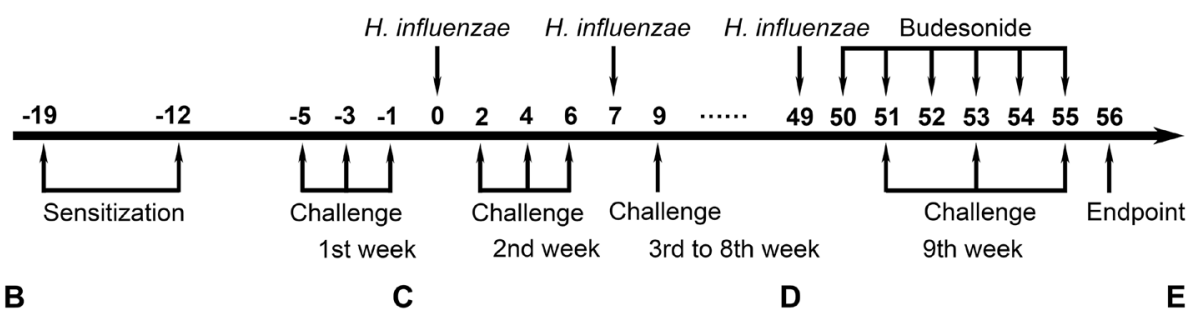

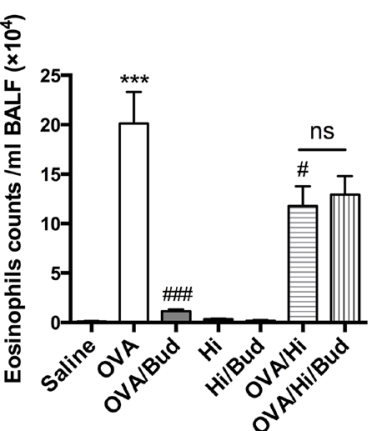

$\mathbf{F}$

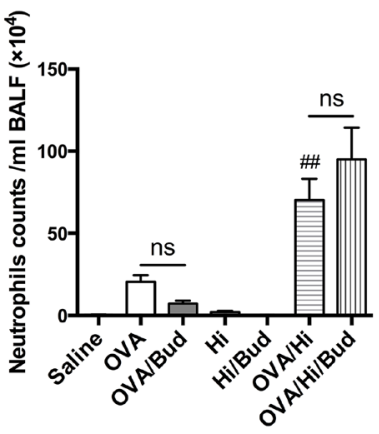

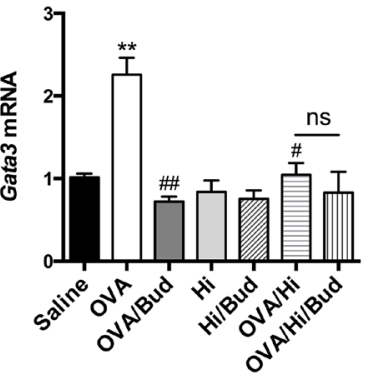

G

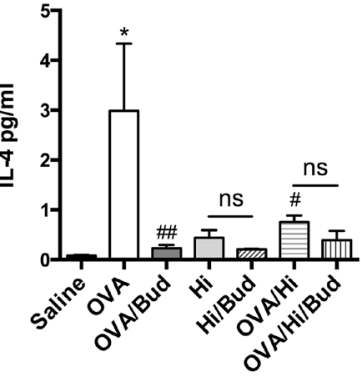

H
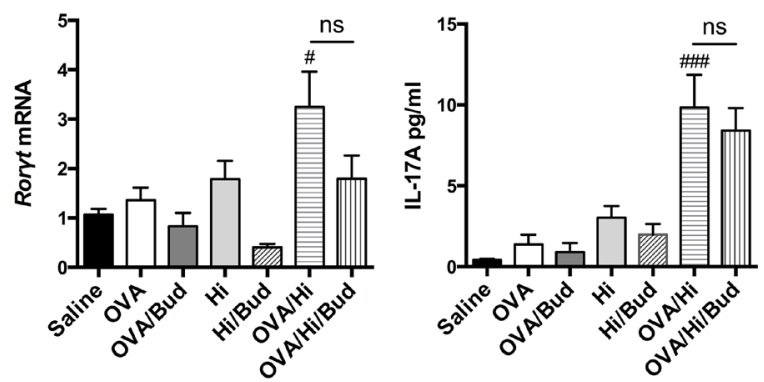
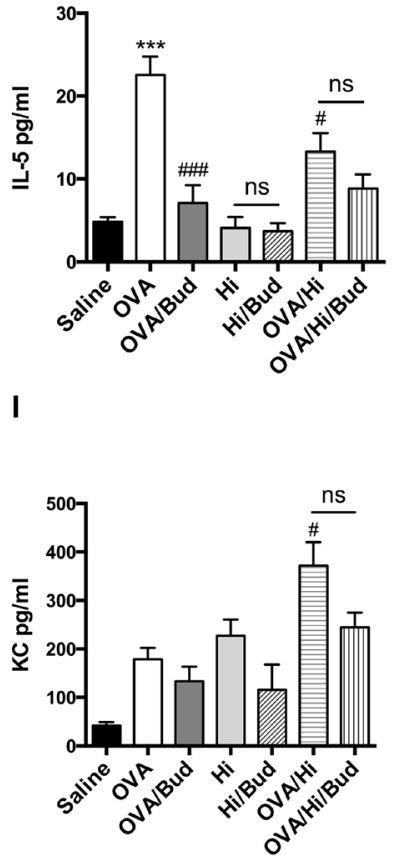

Figure 3: Long-term exposure to low-dose $\boldsymbol{H}$. influenzae during allergic airway disease converts a steroid-sensitive Th2-associated eosinophilic inflammation to a steroid-resistant Th17-associated neutrophilic inflammation. AAD was established and maintained by OVA sensitization twice and challenge three times a week. Long-term exposure to low-dose $H$. influenzae was administered by intranasally inoculation with $1 \times 10^{6} \mathrm{CFU}$ of $H$. influenzae once a week. Budesonide was given via inhalation once per day for 6 consecutive days just before endpoint (A). Eosinophil number (B) in BALF, Gata3 mRNA expression (C) in lung tissue, and levels of IL-4 (D) and IL-5 (E) in BALF were assessed to evaluate Th2-associated eosinophilic inflammation. Neutrophil number (F) in BALF, Roryt mRNA expression (G) in lung tissue, and levels of IL-17 (H) and KC (I) in BALF were assessed to evaluate Th17-associated neutrophilic inflammation. Data presented the mean \pm SEM. Significant differences between saline group and the others are shown as ${ }^{* * *} \mathrm{P}<0.001,{ }^{* *} \mathrm{P}<0.01,{ }^{*} \mathrm{P}<0.05$. Significant differences between OVA groups and the others are shown as ${ }^{\# \# *} \mathrm{P}<0.001,{ }^{\#} \mathrm{P}<0.01,{ }^{\#} \mathrm{P}<0.05$. No significance was ns for short. Hi: Haemophilus influenzae; Bud: budesonide. 
exposure during AAD significantly down regulated the expression of Foxp3 mRNA in lung tissue (Figure 4A). Consistent with that, IL-10 level in BALF was decreased in OVA/Hi group vs. OVA group (Figure 4B). This indicated that long-term bacterial exposure during AAD might cause a defect in anti-inflammatory response. Although treatment with budesonide significantly enhanced the expression of lung Foxp3 mRNA in mice with AAD alone (OVA/Bud group), mice with AAD combined bacterial exposure (OVA/Hi/Bud group) revealed poor response to the treatment (Figure 4A). Similarly, IL-10 level in BALF showed significant decrease after budesonide treatment in mice with AAD alone because of the strong anti-inflammatory effect of steroids, while it was found no decrease after budesonide treatment in allergic mice with long-term bacterial exposure (Figure 4B).

To determine the effects of long-term exposure to $H$. influenzae during AAD on Th1-associated inflammation, expression of Tbx21 mRNA and level of interferon (IFN)- $\gamma$ were assessed. They both had trends of down-regulations in OVA group vs. saline group and up-regulations in OVA/ Hi group vs. OVA group. However, these changes were not significant (Figure 4C-4D). Treatments with budesonide tended to increase their expressions in mice in OVA/Bud, $\mathrm{Hi} / \mathrm{Bud}$ and OVA/Hi/Bud groups compared with their corresponding controls, but no significant differences were found either (Figure 4C-4D).

Collectively, these results indicated that there existed an imbalance between pro-inflammatory response and anti-inflammatory response after long-term exposure to $H$. influenzae during AAD, which might be involved in steroid resistance. However, no significant effects on Th1associated inflammation were found.

\section{Long-term exposure to low-dose $\boldsymbol{H}$. influenzae during allergic airway disease impairs the phagocytosis by macrophage}

We then assessed whether defects in phagocytic capacity might be involved in the mechanism of excessive inflammation in allergic mice with long-term exposure to $H$. influenzae. Phagocytic capacities of $H$. influenzae by both neutrophil and alveolar macrophage in BALF were assessed using flow cytometry. Neutrophils were cells highly expressed CD45 and Gr-1, and macrophages were cells highly expressed CD45 and F4/80. Phagocytosing
A

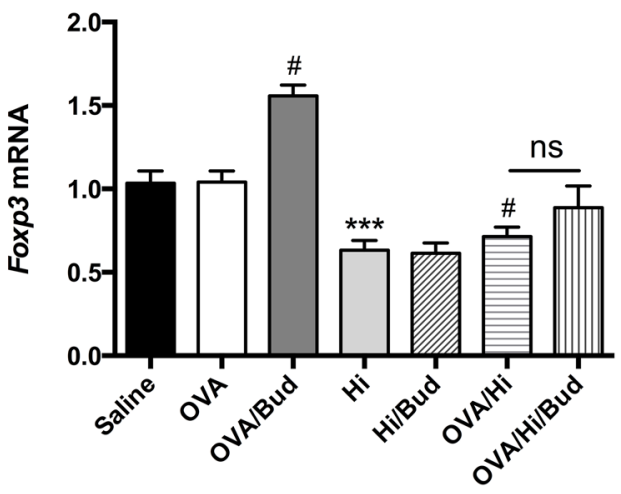

C

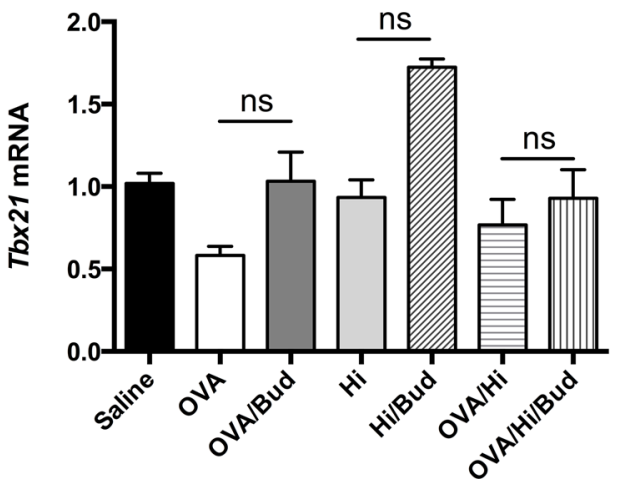

B

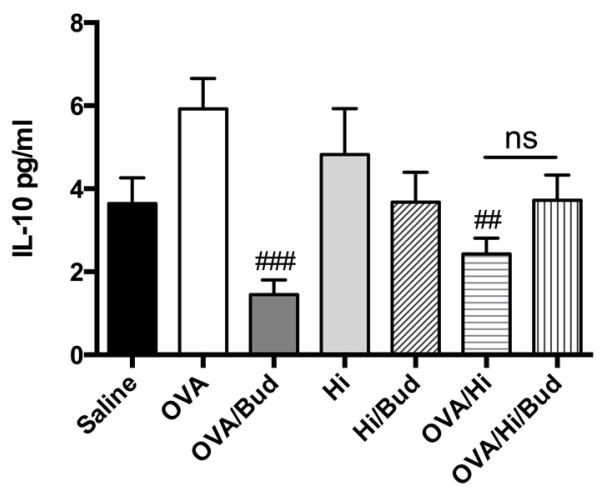

D

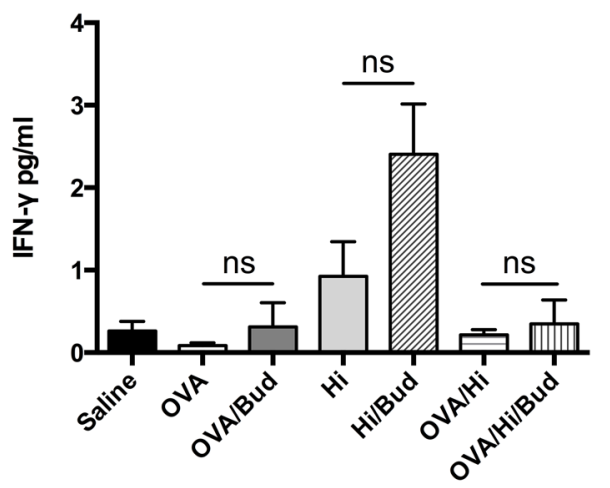

Figure 4: Long-term exposure to low-dose $H$. influenzae during allergic airway disease inhibits Treg-associated immunosuppression but does not affect Th1-associated inflammation. To determine the role of Treg-associated immunosuppression and Th1-associated inflammation, expressions of Foxp3 (A) and Tbx21 (C) mRNAs in lung tissue, levels of IL-10 (B) and IFN- $\gamma$ (D) in BALF were assayed. Data presented the mean \pm SEM. Significant differences between saline group and the others are shown as ${ }^{* * *} \mathrm{P}<0.001$. Significant differences between OVA groups and the others are shown as ${ }^{\# \#} \mathrm{P}<0.001,{ }^{\# \#} \mathrm{P}<0.01,{ }^{*} \mathrm{P}<0.05$. No significance was ns for short. Hi: Haemophilus influenzae; Bud: budesonide. 
cells were those positive for $H$. influenzae-fluorescein isothiocyanate (FITC). Phagocytic capacity was evaluated by mean fluorescence intensity (MFI) of FITC. Representative scatter plots were shown in Figure 5A.

The induction of AAD (OVA group) increased the phagocytosis by both neutrophils and macrophages in BALF (Figure 5B-5E). Compared with that, long- term exposure to $H$. influenzae during AAD (OVA/Hi group) did not suppress the proportion of phagocytosing neutrophils and macrophages (Figure 5B-5C). There was also no significant difference of MFI in neutrophils between OVA/Hi group and OVA group (Figure 5D). However, MFI in macrophages was notably decreased in allergic mice with bacterial exposure compared with

A

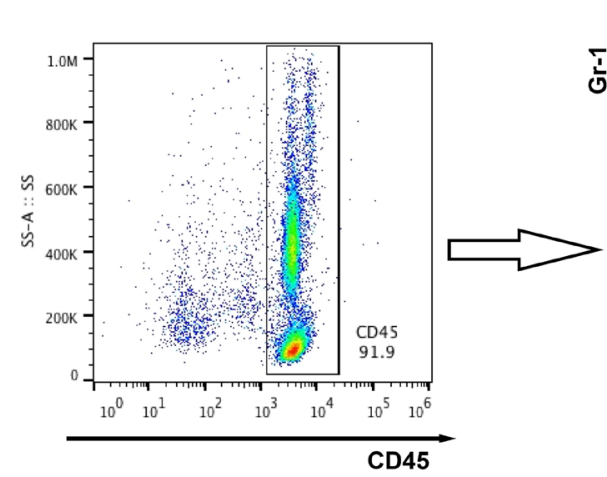

B

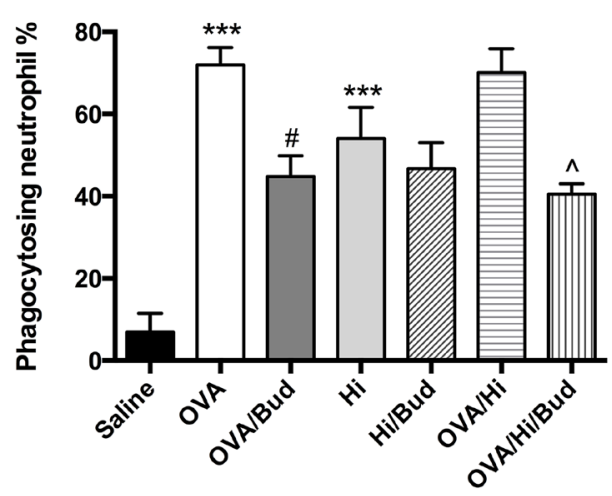

D

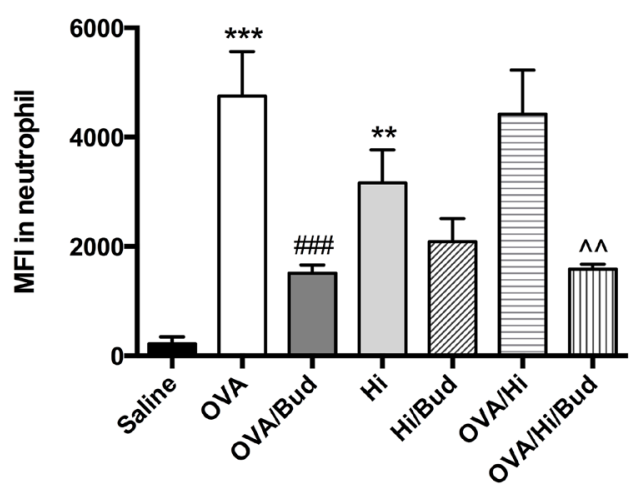

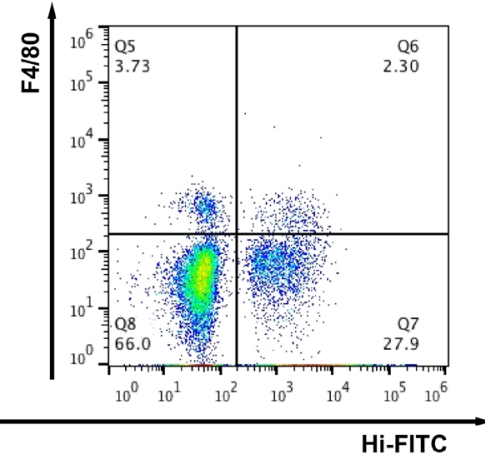

C

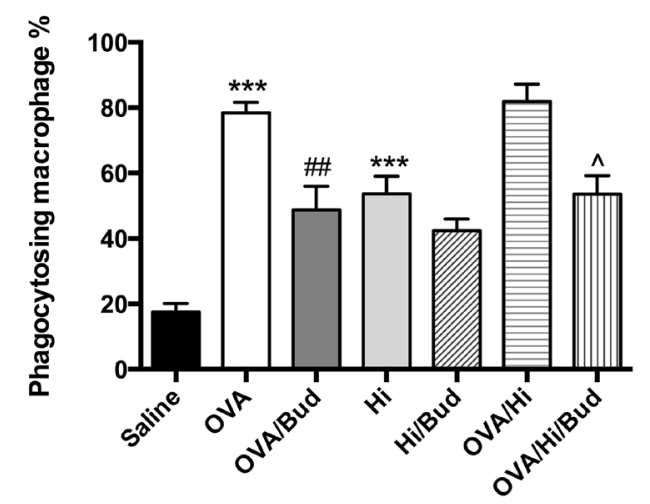

E

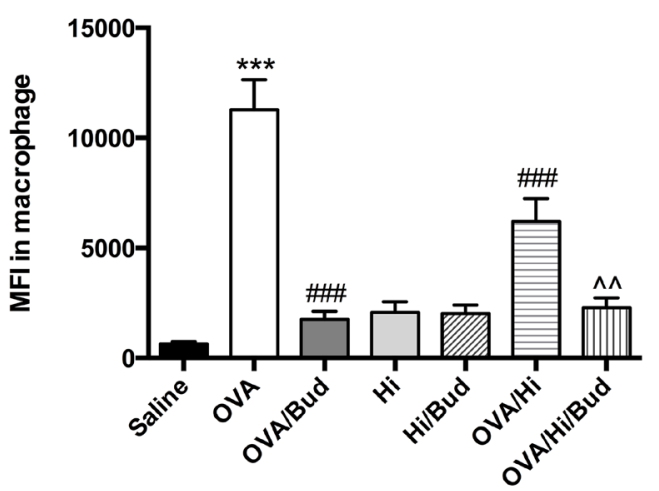

Figure 5: Long-term exposure to low-dose $\boldsymbol{H}$. influenzae during allergic airway disease impairs the phagocytosis by macrophage. BALF cells were obtained. Phagocytic capacities of $H$. influenzae by both neutrophil and alveolar macrophage in BALF were assessed using flow cytometry. Representative scatter plots were shown (A). Among the CD45+ cells, neutrophil was further identified as high expression of Gr-1 while macrophage was further identified as high expression of F4/80. The effects on proportion of phagocytosing neutrophil (B), proportion of phagocytosing macrophage (C), MFI of FITC in neutrophil (D) and MFI of FITC in macrophage (E) were assessed. Data presented the mean \pm SEM. Significant differences between saline group and the others are shown as ${ }^{* * *} \mathrm{P}<0.001,{ }^{* *} \mathrm{P}<0.01$. Significant differences between OVA groups and the others are shown as ${ }^{\# \#} \mathrm{P}<0.001,{ }^{\# \#} \mathrm{P}<0.01,{ }^{\#} \mathrm{P}<0.05$. Significant differences between $\mathrm{OVA} / \mathrm{Hi}$ and the others are shown as ${ }^{\wedge} \mathrm{P}<0.01,{ }^{\wedge} \mathrm{P}<0.05$. Hi: Haemophilus influenzae; Bud: budesonide. 
those without (Figure 5E). Treatment with budesonide did not normalize the defected phagocytosis by macrophage. In contrast, after treatment with budesonide, both neutrophil and macrophage had further impairment in the phagocytosis, including both proportion of phagocytosing cell and MFI (Figure 5B-5E).

These results indicated that long-term exposure to $H$. influenzae during AAD impaired the phagocytosis by macrophage. This defect could not be normalized by budesonide treatment, which might even aggravate that.

\section{Long-term exposure to low-dose $H$. influenzae during allergic airway disease promotes mucus production}

Mucus production helps in bacterial clearance and is involved in the host defense. Periodic acid-Schiff (PAS) staining was conducted to evaluate the mucus production in the lung tissue. Allergic mice (OVA group) exhibited a significant increase in mucus hypersecretion within the bronchi of the lungs, which resembled features of patients with asthma (Figure 6A). When combined longterm bacterial exposure with AAD, mice (OVA/Hi group) showed a further increase in mucus production with higher proportion of PAS positive cells within the bronchi than mice with AAD alone (Figure 6A).

Muc $5 b$ and Muc5ac are genes encoded structurally related mucin glycoproteins, which are the principal macromolecules in airway mucus. Therefore, we subsequently investigated their mRNA expressions in lung tissue. Notably, mice in OVA/Hi group had much higher expression of $M u c 5 b$ but similar expression of Muc5ac compared with those in OVA group (Figure 6B-6C).

After treatment with budesonide, proportion of PAS positive cells in all allergic mice significantly decreased to the control level, accompanied by decreases of $M u c 5 b$ mRNA level in OVA/Hi/Bud group and Muc5ac mRNA levels in both OVA/Bud and OVA/Hi/Bud groups (Figure 6A-6C).

\section{Long-term exposure to low-dose $H$. influenzae during allergic airway disease promotes airway remodeling}

Chronic inflammation is considered as an important factor of airway remodeling, of which, collagen increase and smooth muscle hyperplasia are prominent features [22]. We sought to examine the markers of them. Collagen deposition and muscular layer thickening in subepithelial and perivascular spaces showed increases in allergic mice vs. saline controls, while they were further aggravated in allergic bacteria-exposed mice. Exposed to bacteria alone had no these effects (Figure 7A). The protein levels of markers in lung tissue revealed similar results. The increases of $\alpha$-smooth muscle actin ( $\alpha$-SMA) and several primary types of collagens in airway remodeling in mice with AAD alone, including collagen $\alpha 1$ type 1 (COL1A1), collagen $\alpha 2$ type 1 (COL1A2) and collagen $\alpha 1$ type 3 (COL3A1), were robustly aggravated after long-term exposure to $H$. influenzae (OVA/Hi group vs. OVA group). Exposure to bacteria alone had no above effects (Figure 7B-7C).

Budesonide treatment showed no obvious viable effects on collagen deposition and smooth muscle hyperplasia on lung sections with Masson staining (Figure 7A). However, the protein levels of $\alpha$-SMA, COL1A1, COL1A2, and COL3A1 all significantly decreased in mice with AAD alone after budesonide treatment (OVA/ Bud group vs. OVA group) (Figure 7B-7C). In allergic bacteria-exposed mice, the levels of above proteins also tended to decrease but not significant (OVA/Hi/Bud group vs. OVA/Hi group) (Figure 7B-7C).

Collectively, these results indicated that long-term bacterial exposure during AAD might promote deposition of extracellular matrix and hyperplasia of smooth muscle, thus promoted airway remodeling. Budesonide treatment might remit this pro-remodeling effect, but allergic mice with long-term bacterial exposure also showed poor response to that.

\section{DISCUSSION}

In the present study, we established a murine model of long-term airway bacterial exposure, to simulate the slight inflammation of bacterial colonization, showing that during OVA-induced AAD, long-term exposure to lowdose $H$. influenzae induced a Th17-related and steroidresistant airway neutrophilic inflammation, and resulted in airway hypersecretion and remodeling acceleration. We also indicated that defects in Treg-associated antiinflammatory mechanism and phagocytosis of airway macrophages might be responsible for the excessive neutrophilic inflammation.

For the establishment of the long-term model, symptoms, body weight, airway inflammation and detection of bacteria within a week after transient exposure were firstly investigated. Mice exposed to $1 \times 10^{6} \mathrm{CFU}$ of $H$. influenzae had no obvious symptoms and body weight changes, but most of them had persistent detectable bacterial recovery in the BALF. The accompanied airway inflammation was slight, went through an acute phase and was resolved at day 7 postinfection. We further applied this dose of $H$. influenzae to a long-term model in both non-allergic and allergic mice by repeating inoculation once a week. Similar to the outcomes induced by transient exposure, no sigh of disease, body weight loss or serious infection appeared in inoculated mice. In contrast, $H$. influenzae with the dose of $1 \times 10^{7} \mathrm{CFU}$, which applied as the positive control, induced serious infections. These findings suggest that $1 \times 10^{6} \mathrm{CFU}$ is appropriate for the long-term model and can simulate the slight airway inflammation of colonization. 
In the long-term model, we showed that in allergic mice, exposure to $H$. influenzae significantly converted the inflammatory phenotype from a Th2-associated eosinophilic inflammation to a Th17-associated neutrophilic inflammation. Notably, the intense increase of airway neutrophilic inflammation was not observed in non-allergic mice that exposed to the same dose of $H$. influenzae. This indicates that this bacteria-induced neutrophilic inflammation in the present study does not result from the infectious process and allergic airway inflammation may increase the susceptibility to that. The shift of asthma inflammatory phenotype may be attributed to the component of $H$. influenzae, lipopolysaccharide
(LPS), as previously reported [23]. Although Th2 associated eosinophilic inflammation is the hallmark of allergic asthma, Th17/IL-17 is reported elevated in severe asthma [24], resulting in increased neutrophils in airways [25]. In addition, IL-17 is also reported to mediate innate and adaptive immunity to aid in host defense against bacterial infections [26]. Here, our results suggest that Th17/IL-17 might be the link between bacterial exposure and severe neutrophilic asthma.

Inhaled corticosteroids (ICS) are mainstay of asthma therapy. However, patients with neutrophilic asthma usually do not respond well to them [5]. Our results demonstrated that allergic mice with long-term exposure

A

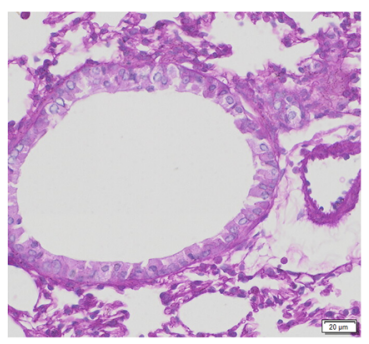

Saline

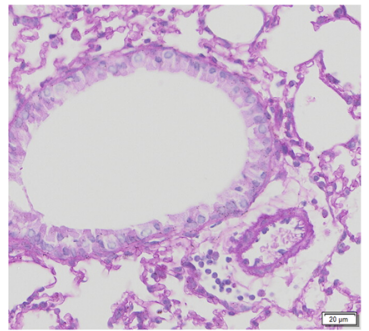

Hi

B

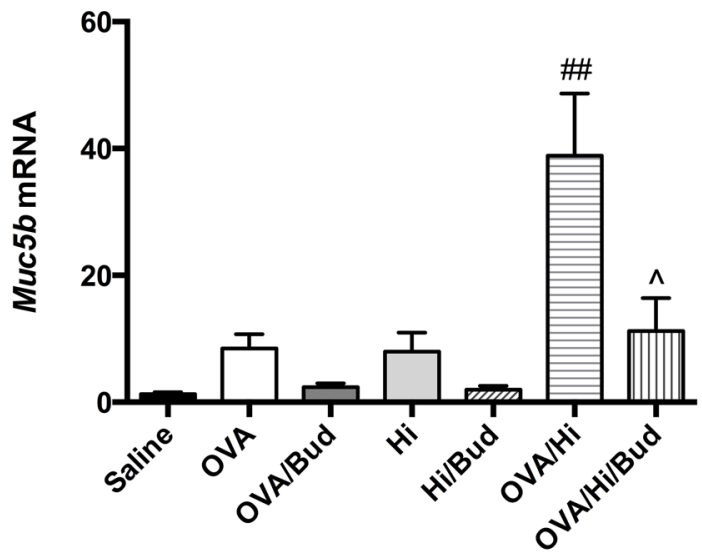

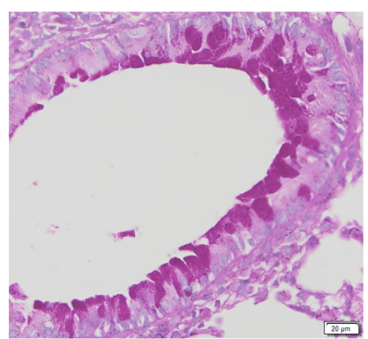

OVA

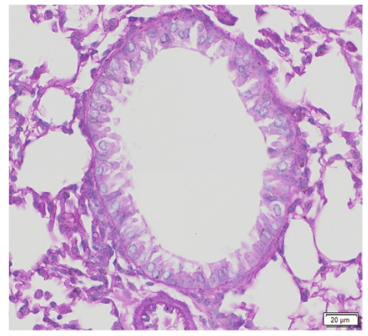

Hi/Bud

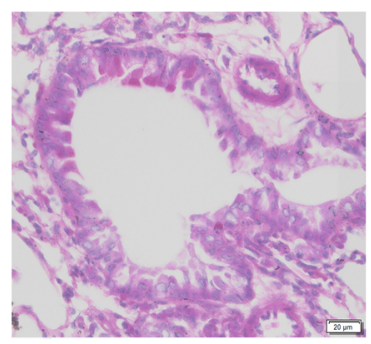

OVA/Bud

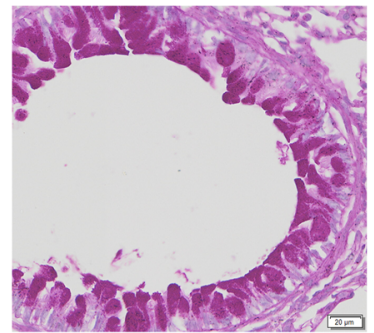

OVA/Hi

C

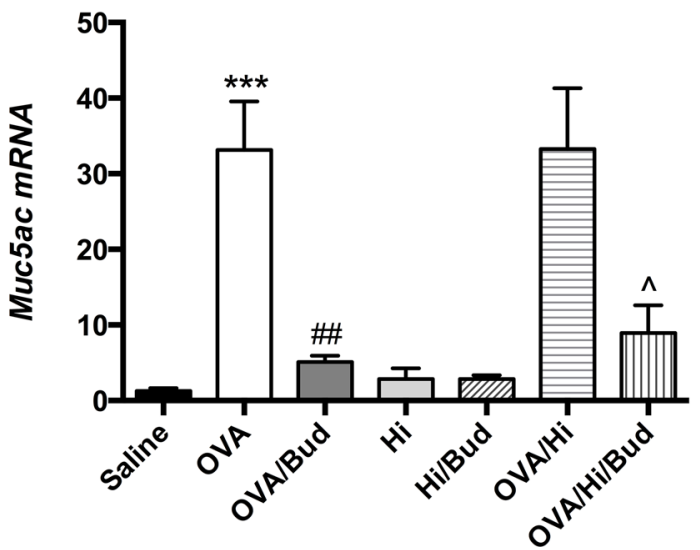

Figure 6: Long-term exposure to low-dose $\boldsymbol{H}$. influenzae during allergic airway disease promotes mucin production. Mucus production was evaluated by PAS staining (A, original magnification: $\times 200)$. Expressions of Muc5b (B) and Muc5ac (C) mRNAs in lung tissue were further evaluated. Data presented the mean \pm SEM. Significant differences between saline group and the others are shown as ${ }^{* * *} \mathrm{P}<0.001$. Significant differences between OVA groups and the others are shown as ${ }^{{ }^{\#}} \mathrm{P}<0.01$. Significant differences between OVA/Hi groups and the others are shown as ${ }^{\wedge} \mathrm{P}<0.05$. Hi: Haemophilus influenzae; Bud: budesonide. 
to $H$. influenzae showed a resistance to budesonide treatment, which resembled patients with neutrophilic asthma. This resistance may partly be attributed to Th17 cells. In patients with asthma, elevated expression of Th17 cytokine, IL-17, is found associated with neutrophilic inflammation, disease severity and high dose of steroid treatment [25]. An animal experiment shows that transfer of Th17 cells to allergic mice results in airway neutrophilic inflammation and airway hyperresponsiveness, and both of them cannot be attenuated by dexamethasone [27]. A possible mechanism for IL-17 associated glucocorticoid insensitivity is that, IL-17 is able to increase the expression
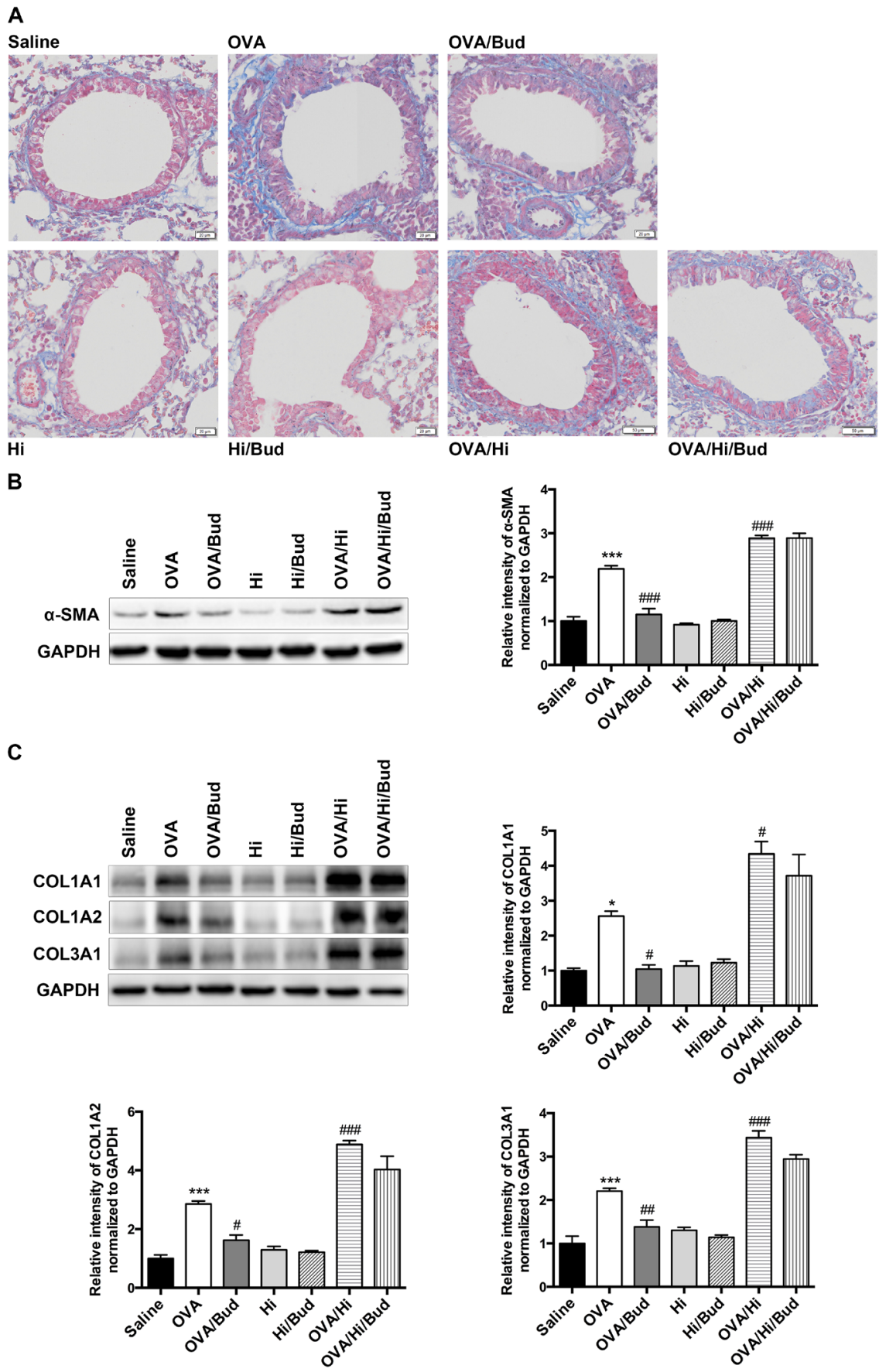

Figure 7: Long-term exposure to low-dose $\boldsymbol{H}$. influenzae during allergic airway disease promotes airway remodeling. Airway remodeling was assessed by image analysis and protein levels of markers in lung tissue. Masson staining (A, original magnification: $\mathrm{OVA} / \mathrm{Hi}$ and $\mathrm{OVA} / \mathrm{Hi} / \mathrm{Bud}, \times 132$; others, $\times 200$ ) showed collagen (blue) and smooth muscle layer (red) in the subepithelial and perivascular spaces. Western blot showed protein levels of $\alpha$-SMA (B), COL1A1 (C), COL1A2 (C) and COL3A1 (C). Data presented the mean \pm SEM. Significant differences between saline group and the others are shown as ${ }^{* * *} \mathrm{P}<0.001,{ }^{*} \mathrm{P}<0.05$. Significant differences between $\mathrm{OVA}$ groups and the others are shown as ${ }^{\# \#} \mathrm{P}<0.001,{ }^{\#} \mathrm{P}<0.01,{ }^{\#} \mathrm{P}<0.05$. Hi: Haemophilus influenzae; Bud: budesonide. 
of glucocorticoid receptor (GR)- $\beta$, which is an inhibitor of GR- $\alpha$ and can inhibit the activation of the receptor [28]. Whether long-term bacterial exposure inhibits the activation of the receptor via IL-17 induced GR- $\beta$ increase needs further investigation.

Treg cells play a key role in immune tolerance and inhibit excessive inflammatory response [29]. However, compared with those in allergic mice alone, Treg-associated transcriptional factor and cytokine, Foxp3 and IL-10, significantly down regulated in allergic mice combined with bacterial exposure. The block of IL-10 related signal may significantly augment airway neutrophilia in asthma [30]. Thus defects in Treg related anti-inflammatory mechanisms might be involved in the production of excessive neutrophilic inflammation and shift of inflammatory phenotype in mice combined with bacterial exposure and AAD. In addition, although in allergic mice, budesonide treatment significantly elevated the expression of Foxp 3 mRNA in the lung, no treatment response was found in allergic bacteria-exposed mice. Corticosteroid therapy is reported to exert its antiinflammatory effect partly by elevating Treg cells [31]. Thus, the failure to induce Treg-associated suppression of inflammation may be also involved in steroid-resistance.

Recent data suggest that Th1-associated inflammation, which helps to combat and eliminate pathogens, also plays a role in severe steroid-resistant asthma [32]. However, in the current model, although Th1-associated factors, Tbx21 mRNA and IFN- $\gamma$, tended to increased expressions in mice in OVA/Hi group vs. OVA group, no significances were found. Similar results were reported previously [23]. Bacterial infections may promote pathogenesis of severe asthma. However, the inflammatory response involved in the mechanism varies with the species and dose of bacteria $[17,18]$. This suggests that, in addition to the common pathway, there probably exists other mechanisms depending on the species and dose of bacteria, which may contribute to the heterogenity of the inflammation. A large dose of bacteria is probably needed to promote predominant Th1 responses [33]. However, the dose of $H$. influenzae used in our model was low, insufficient to induce an active airway infection, and in this case, Th1-associated inflammation was not found significantly promoted.

Innate immunity is activated in patients with neutrophilic asthma [34]. Neutrophils and macrophages are key cellular components of innate immunity, which act in pathogens phagocytosis and elimination. Therefore, we investigated the effect of bacterial exposure in AAD on their phagocytosis. Our results demonstrated that, after long-term exposure to bacteria, the MFI of airway macrophage in allergic mice significantly decreased, indicating that although there was no change in the number of macrophage that participating in the phagocytosis, the average amount of engulfed bacteria per cell had been dramatically decreased. Similar to our results, macrophage phagocytosis is also reported impaired in severe asthma [35], non-eosinophilic asthma [36], and poorly controlled asthma [37]. The mechanism of the impaired phagocytosis in allergic bacteria-exposed mice has not been fully elucidated. It may be the direct result of bacterial exposure. But on the other hand, the innate immunity responding to LPS is impaired in asthmatic patients compared with healthy controls [38]. LPS stimulation does not alter phagocytosis of bacteria by alveolar macrophage in healthy controls but decreases the phagocytosis in moderate to severe asthmatic patients [37]. These evidences suggest that allergy itself may also play an important role in it. Therefore, the impaired phagocytosis may be due to a complex interplay between immune changes in AAD and long-term bacterial exposure. Defects in phagocytosis may lead a failure in bacterial clearance and induce the persistence of excessive inflammation. ICS treatment can not normalize the phagocytosis [39], and even further decrease it [40], consistent with what we found in the present study.

Production of mucus is one character of asthma, but also helps in bacterial clearance. We found that longterm bacterial exposure significantly increased the mucus secretion in mice with AAD. Interestingly, in allergic mice, Muc5ac expression was predominant, while in bacteria-exposed allergic mice, it maintained at the same level, but $M u c 5 b$ expression showed a significant increase. This may be a response to bacteria, since it is mucin MUC5B, but not mucin MUC5AC, that contributes to mucociliary clearance [41]. Treatment with budesonide significantly inhibited the airway hypersecretion. However, this effect may also impair the mucociliary clearance. The inhibitory effects of ICS on mucociliary clearance and phagocytosis may be responsible for the increased risk of pneumonia in patients taking ICS treatments [42].

Chronic inflammation may promote airway remodeling, which will lead to irreversible airway obstruction and promote fixed airflow limitation in asthma. Extracellular matrix deposition and hyperplasia of airway smooth muscle cells are two important features of airway remodeling [22]. In allergic mice, eosinophils secrete several proteins and cytokines, such as eosinophil cationic proteins, peroxidase and transforming growth factor- $\beta$, to mediate the tissue damage and remodeling $[43,44]$. When eosinophilic inflammation was inhibited by treatment with budesonide, we found a significant decrease of the synthesis of $\alpha$-SMA and collagens in lung tissue. However, in bacteria-exposed allergic mice, although eosinophilic inflammation was inhibited by bacterial exposure, expression of $\alpha$-SMA and collagens in the lungs significantly increased than those in allergic mice, indicating that long-term bacterial exposure notably promoted airway remodeling in AAD. On the one hand, the inhibitory effect of bacteria on eosinophilic inflammation is weaker than that of budesonide; on the 
other hand, bacterial exposure induces an excessive neutrophilic inflammation. Neutrophils also release key factors mediating airway remodeling, such as matrix metalloproteinase, elastase and myeloperoxidase [45]. When stimulated by LPS, neutrophils also release exosome, which contains several proteins associated with airway remodeling, and enhance hyperplasia of airway smooth muscle by exosome internalization [46]. In allergic mice combined with bacterial exposure, treatment with budesonide did not decrease the expression of $\alpha$-SMA and collagens in the lung. This may be due to the steroidresistance of the airway inflammation, and suggests that asthmatic patients with long-term bacterial colonization might not slow down the rate of progress to airway remodeling, even if taking the ICS treatments.

In conclusion, we successfully simulate the slight airway inflammation of long-term bacterial colonization in a mouse model, indicating that, during AAD, long-term exposure to a low-dose $H$. influenzae drives an increased neutrophilic airway inflammation. This inflammation is associated with an activation of Th17 immune response and a suppression of Th2 immune response, and characterized by a resistance to ICS treatment. Persistent neutrophilic inflammation may be partly attributed to defects in Treg-associated anti-inflammatory mechanism and macrophage phagocytosis, and may promote airway hypersecretion and remodeling. These characteristics resemble features of patients with neutrophilic asthma. These results contribute to our understanding of the roles of bacterial colonization in the pathogenesis and progression of neutrophilic asthma, and suggest that in asthmatic patients, airway bacterial colonization may be a potential therapeutic target. Minimizing the pathogen burden in airway, such as $H$. influenzae, may be beneficial.

\section{MATERIALS AND METHODS}

\section{Mice}

Female 6-8 week-old BALB/c mice were purchased from Chongqing Experimental Animal Center (Chongqing, China). Mice were maintained under pathogen-free conditions at the animal center of Xinqiao Hospital, with ad libitum access to food and water, and subjected to a light-dark cycle of 12 hours. The Ethics Committee of Xinqiao Hospital approved all the experiments. The use of animals in these experiments was in accordance with the guidelines issued by the Chinese Council on Animal Care and the U. S. Public Health Service Policy on Humane Care and Use of Laboratory Animals.

\section{Haemophilus influenzae}

Haemophilus influenzae (ATCC 49247, USA) was grown on chocolate agar (Pangtong Co., Chongqing, China) in $5 \% \mathrm{CO}_{2}$ at $37{ }^{\circ} \mathrm{C}$ for 20 hours. For bacterial administration, live $H$. influenzae was harvested from the plate and resuspended in saline for intranasally inoculation. For in vitro phagocytosis assay, harvested $H$. influenzae was heat-inactivated at $70{ }^{\circ} \mathrm{C}$ for one hour, subsequently labeled with FITC (Sigma, USA) according to manufacturer's instructions, and finally adjusted to $1 \times$ $10^{9} \mathrm{CFU} / \mathrm{ml}$.

\section{Experimental protocols}

To establish an AAD, on days -19 and -12 , BALB/c mice were sensitized via intraperitoneal (i.p.) injection with $100 \mu \mathrm{g}$ of OVA (Grade V, Sigma-Aldrich, USA), absorbed to $4 \mathrm{mg}$ of Imject Alum (Thermo, USA) in $200 \mu \mathrm{l}$ of a sterilized $0.9 \%$ saline. Beginning on day -5 , the mice were challenged through the respiratory tract with $1 \%$ aerosolized OVA in saline for 30 minutes three times a week. Non-allergic controls were received saline sensitization and challenge.

Twenty-four hours after the third challenge every week, mice were anesthetized via i.p. injection with 50 $\mathrm{mg} / \mathrm{kg}$ of pentobarbital (Dingguo Co., Ltd., Beijing, China) and intranasally inoculated with live $H$. influenzae. Appropriate dose for the model of long-term exposure would be determined through a transient exposure in nonallergic mice. Saline control group and AAD alone group were intranasally instilled with saline instead.

Budesonide treatment was performed as previously reported with minor modification [47]. Briefly, mice were treated nasally with nebulized budesonide once per day for 6 consecutive days in the last week just before endpoint, with the manner similar to that of OVA challenge. Budesonide was diluted to $0.125 \mathrm{mg} / \mathrm{ml}$. Each mouse was allowed to breath in the aerosol for 2 minutes. The dose given to each mouse was thus equivalent to a $1000 \mu \mathrm{g}$ dose for an adult. Untreated mouse were exposed to saline.

Seven days after the 8th colonization and 24 hours after the last challenge (day 56), mice were sacrificed via lethally anesthetization for analyses.

\section{Body weight}

Body weights were measured before every inoculation and just before the final sacrifice.

\section{Bronchoalveolar lavage}

Bronchoalveolar lavage was performed as described before [23]. Briefly, a tube was inserted into the trachea and lavaging was performed three times consecutively with $1 \mathrm{ml}$ of ice-cold saline. A total of $0.15 \mathrm{ml}$ of BALF was removed for bacterial recovery. Total cell counting was then performed using a haemocytometer. After that, the remaining BALF was centrifuged at $400 \times \mathrm{g}$ at $4{ }^{\circ} \mathrm{C}$ for 5 minutes. Cell pellets were resuspended with phosphatebuffered saline (PBS, HyClone, USA) to a concentration 
of $1 \times 10^{7} / \mathrm{ml}$ for subsequent flow cytometry analysis and cell differential counting via Wright-Giemsa staining (BASO Co., Zhuhai, China). Supernatants were harvested and stored at $-80{ }^{\circ} \mathrm{C}$ until cytokines analyses.

\section{Bacterial recovery}

A total of $0.1 \mathrm{ml}$ of serial dilutions of BALF were plated onto chocolate agar plates (Pangtong Co., Chongqing, China) and incubated in $5 \% \mathrm{CO}_{2}$ at $37^{\circ} \mathrm{C}$ for 24-48 hours. Colonies were enumerated and then the actual bacterial CFU were calculated in BALF.

\section{Flow cytometry}

A flow cytometric method was used to determine the phagocytic capacity of $H$. influenzae by neutrophils and alveolar macrophages. FITC labeled $H$. influenzae was adjusted to $1 \times 10^{9} \mathrm{CFU} / \mathrm{ml}$ and added to resuspended BALF cells $\left(1 \times 10^{7} / \mathrm{ml}\right)$. After incubated at $37^{\circ} \mathrm{C}$ for 10 minutes, cells were washed with PBS to remove potentially excessive extracellular bacteria and subsequently stained with the following fluorochrome-labeled antibodies (all obtained from Biolegend, USA): PerCP/Cy5.5-CD45, PEF4/80 and APC-Cy7-Gr1. The cells were incubated with these antibodies for 30 minutes at $4{ }^{\circ} \mathrm{C}$ in the dark. Then they were washed, resuspended with PBS and detected using a Beckman Coulter (Galios, USA) flow cytometry. Among all the cells positive for CD45, neutrophils were defined by positive staining for Gr1 and alveolar macrophage were defined by positive staining for F4/80. Phagocytosing cells were those positive for $H$. influenzaeFITC. Phagocytic capacity was evaluated by MFI of FITC. Flow cytometry data were analysed with Flowjo software (version 10.0.7).

\section{Cytokine analysis}

Cytokine levels were determined using a Mouse High Sensitivity T Cell Magnetic Bead Panel kit (Merck Millipore, Germany) according to the manufacturer's instructions.

\section{Lung histology}

The left lungs were harvested, fixed with $4 \%$ paraformaldehyde and embedded in paraffin after dehydration. Then, $6 \mu \mathrm{m}$ sections of embedded lung tissue were mounted onto slides and stained with hematoxylin and eosin to identify tissue inflammation, with PAS reagent to identify mucus production, and with Masson trichrome to evaluate the collagen deposition and smooth muscle hyperplasia. Tissue sections were viewed with Olympus BX61VS microscope (Japan) and OlyVIA software (Japan).

\section{Reverse transcription-polymerase chain reaction (RT-PCR)}

Lower lobe of right lungs were removed and immersed in RNAlater ${ }^{\mathrm{TM}}$ Solution (Invitrogen, USA). Total RNA was extracted using TRIzol $^{\mathrm{TM}}$ Reagent (Invitrogen, USA). cDNA was prepared from total RNA using QuantiNova ${ }^{\mathrm{TM}}$ Reverse Transcription Kit (Qiagen, Germany) according to the manufacturer's instructions. Quantitative PCR was performed using QuantiNova ${ }^{\mathrm{TM}}$ SYBR ${ }^{\circledR}$ Green PCR kit (Qiagen, Germany) on Rotor Gene (Qiagen, Germany) according to the manufacturer's instructions. Primers (all synthesized by SANGON Biotech, Shanghai, China) were: mouse Gapdh, F 5'-GACGGCCGCATCTTCTTGT-3', R 5'-ACACCGACCTTCACCATTTTGT-3'; mouse Tbx21, F 5'-AGCAAGGACGGCGAATGTT-3', R 5'-GGGTGGACATATAAGCGGTTC-3'; mouse Gata3, F 5'-CTCGGCCATTCGTACATGGAA-3', R 5'-GGATACCTCTGCACCGTAGC-3'; mouse Roryt, F 5'-AGCACTGACGGCCAACTTACTC-3', R 5'-CGCTGCCGTAGAAGGTCCTC-3'; mouse Foxp3, F 5'-CCCTTTCACCTATGCCACCCTTATC-3', R 5'-GGCGGGGTGGTTTCTGAAGTAGG-3'; mouse $M u c 5 b$, F 5'-TCACCGGAGACAGTCAGAGAG-3', R 5'-GGTGTAAGGCGCTCATGCTA-3'; mouse Muc5ac, F 5'-CACTGGAGCTGGATGTCAGA-3', R 5'-ACACAGCCTCCATTTCCATC-3'.

\section{Western blot}

Upper lobe of right lungs were removed and homogenized in a tissue protein extraction reagent (Thermo, USA). The lysates were centrifuged at $16000 \times$ $\mathrm{g}$ at $4{ }^{\circ} \mathrm{C}$ for 15 minutes to remove insoluble protein. The protein concentrations were determined and subsequently separated using SDS-PAGE. Separated proteins were transferred to PVDF membranes (Millipore, Germany), blocked with $5 \%$ skimmed milk, and then incubated at $4{ }^{\circ} \mathrm{C}$ overnight using the following primary antibodies: a-SMA (ab5649, Abcam, USA), COL1A1 (sc-293182, Santa Cruz, USA), COL1A2 (sc-393537, Santa Cruz, USA), COL3A1 (sc-271249, Santa Cruz, USA), GAPDH (60004, Proteintech, USA). The membranes were washed three times, incubated for 1 hour using horseradish peroxidase-conjugated secondary antibodies and then visualized using an enhanced chemiluminescence detection kit (Amersham Pharmacia, Piscataway, NJ).

\section{Statistical analysis}

Data were presented as the mean \pm standard error of the mean (SEM). Statistical analyses for multiple comparisons were performed via one-way ANOVA with the Bonferronni post-test using Graphpad Prism (version 6). One-way repeated measures ANOVA was used to 
analyze body weight data using IBM SPSS Statistics software (version 22.0). $\mathrm{P}<0.05$ were considered statistically significant.

\section{Abbreviations}

AAD: allergic airway disease; OVA: ovalbumin; Th: $\mathrm{T}$ helper; Treg: regulatory T cell; BALF: bronchoalveolar lavage fluids; CFU: colony-forming units; IL: interleukin; KC: keratinocyte chemokine; IFN: interferon; FITC: fluorescein isothiocyanate; MFI: mean fluorescence intensity; PAS: Periodic acid-Schiff; $\alpha$-SMA: $\alpha$-smooth muscle actin; COL1A1: collagen $\alpha 1$ type 1 ; COL1A2: collagen $\alpha 2$ type 1 ; COL3A1: collagen $\alpha 1$ type 3 ; LPS: lipopolysaccharide; ICS: inhaled corticosteroid; GR: glucocorticoid receptor; PBS: phosphate-buffered saline; RT-PCR: reverse transcription-polymerase chain reaction; SEM: standard error of the mean.

\section{Author contributions}

Changzheng Wang supervised the work; Xu Yang, Shengtao Zhao, and Changzheng Wang designed the study; Xu Yang, Yijie Wang, and Ran Wang performed experiments; Xu Yang analysed the data; and Xu Yang and Changzheng Wang co-wrote the manuscript. All authors read and approved the final manuscript.

\section{ACKNOWLEDGMENTS}

We are grateful to Lingfei Li for his help with experiments and data analysis. We are also grateful to Qiao Zhang for her useful suggestions.

\section{CONFLICTS OF INTEREST}

The authors declare no conflicts of interest.

\section{FUNDING}

This work was supported by grants from the National Natural Science Foundation of China (No. 81270075) awarded to Changzheng Wang.

\section{REFERENCES}

1. McGrath KW, Icitovic N, Boushey HA, Lazarus SC, Sutherland ER, Chinchilli VM, Fahy JV, and Asthma Clinical Research Network of the National Heart, Lung, and Blood Institute. A large subgroup of mild-to-moderate asthma is persistently noneosinophilic. Am J Respir Crit Care Med. 2012; 185:612-19. https://doi.org/10.1164/ recm.201109-1640OC.

2. Simpson JL, Scott R, Boyle MJ, Gibson PG. Inflammatory subtypes in asthma: assessment and identification using induced sputum. Respirology. 2006; 11:54-61. https://doi. org/10.1111/j.1440-1843.2006.00784.x.

3. Moore WC, Hastie AT, Li X, Li H, Busse WW, Jarjour NN, Wenzel SE, Peters SP, Meyers DA, Bleecker ER, and National Heart, Lung and Blood Institute's Severe Asthma Research Program. Sputum neutrophil counts are associated with more severe asthma phenotypes using cluster analysis. J Allergy Clin Immunol. 2014; 133:1557-63.e5. https://doi. org/10.1016/j.jaci.2013.10.011.

4. Shaw DE, Berry MA, Hargadon B, McKenna S, Shelley MJ, Green RH, Brightling CE, Wardlaw AJ, Pavord ID. Association between neutrophilic airway inflammation and airflow limitation in adults with asthma. Chest. 2007; 132:1871-75. https://doi.org/10.1378/chest.07-1047.

5. Berry M, Morgan A, Shaw DE, Parker D, Green R, Brightling C, Bradding P, Wardlaw AJ, Pavord ID. Pathological features and inhaled corticosteroid response of eosinophilic and non-eosinophilic asthma. Thorax. 2007; 62:1043-49. https://doi.org/10.1136/thx.2006.073429.

6. Charlson ES, Bittinger K, Haas AR, Fitzgerald AS, Frank I, Yadav A, Bushman FD, Collman RG. Topographical continuity of bacterial populations in the healthy human respiratory tract. Am J Respir Crit Care Med. 2011; 184:957-63. https://doi.org/10.1164/rccm.201104-0655OC.

7. Huang YJ, Nelson CE, Brodie EL, Desantis TZ, Baek MS, Liu J, Woyke T, Allgaier M, Bristow J, Wiener-Kronish JP, Sutherland ER, King TS, Icitovic N, et al. Airway microbiota and bronchial hyperresponsiveness in patients with suboptimally controlled asthma. J Allergy Clin Immunol. 2011; 127:372-81.e1-3. https://doi.org/10.1016/j. jaci.2010.10.048.

8. Durack J, Lynch SV, Nariya S, Bhakta NR, Beigelman A, Castro M, Dyer AM, Israel E, Kraft M, Martin RJ, Mauger DT, Rosenberg SR, Sharp-King T, et al. Features of the bronchial bacterial microbiome associated with atopy, asthma, and responsiveness to inhaled corticosteroid treatment. J Allergy Clin Immunol. 2017; 140:63-75. https://doi.org/10.1016/j.jaci.2016.08.055.

9. Marri PR, Stern DA, Wright AL, Billheimer D, Martinez FD. Asthma-associated differences in microbial composition of induced sputum. J Allergy Clin Immunol. 2013; 131:34652.e1-3. https://doi.org/10.1016/j.jaci.2012.11.013.

10. Huang YJ, Nariya S, Harris JM, Lynch SV, Choy DF, Arron JR, Boushey H. The airway microbiome in patients with severe asthma: associations with disease features and severity. J Allergy Clin Immunol. 2015; 136:874-84. https://doi.org/10.1016/j.jaci.2015.05.044.

11. Taylor SL, Leong LE, Choo JM, Wesselingh S, Yang IA, Upham JW, Reynolds PN, Hodge S, James AL, Jenkins C, Peters MJ, Baraket M, Marks GB, et al. Inflammatory phenotypes in patients with severe asthma are associated with distinct airway microbiology. J Allergy Clin Immunol. 2018; 141:94-103.e15. https://doi.org/10.1016/j. jaci.2017.03.044. 
12. Liu W, Liu S, Verma M, Zafar I, Good JT, Rollins D, Groshong S, Gorska MM, Martin RJ, Alam R. Mechanism of Th2/Th17-predominant and neutrophilic, Th2/Th17-low subtypes of asthma. J Allergy Clin Immunol. 2017; 139:15481558.e4. https://doi.org/10.1016/j.jaci.2016.08.032.

13. Bisgaard H, Hermansen MN, Bønnelykke K, Stokholm J, Baty F, Skytt NL, Aniscenko J, Kebadze T, Johnston SL. Association of bacteria and viruses with wheezy episodes in young children: prospective birth cohort study. BMJ. 2010; 341:c4978. https://doi.org/10.1136/bmj.c4978.

14. Wood LG, Simpson JL, Hansbro PM, Gibson PG. Potentially pathogenic bacteria cultured from the sputum of stable asthmatics are associated with increased 8-isoprostane and airway neutrophilia. Free Radic Res. 2010; 44:146-54. https://doi.org/10.3109/10715760903362576.

15. Green BJ, Wiriyachaiporn S, Grainge C, Rogers GB, Kehagia V, Lau L, Carroll MP, Bruce KD, Howarth PH. Potentially pathogenic airway bacteria and neutrophilic inflammation in treatment resistant severe asthma. PLoS One. 2014; 9:e100645. https://doi.org/10.1371/journal. pone. 0100645 .

16. Schwerk N, Brinkmann F, Soudah B, Kabesch M, Hansen G. Wheeze in preschool age is associated with pulmonary bacterial infection and resolves after antibiotic therapy. PLoS One. 2011; 6:e27913. https://doi.org/10.1371/journal. pone. 0027913 .

17. Whitehead GS, Thomas SY, Cook DN. Modulation of distinct asthmatic phenotypes in mice by dose-dependent inhalation of microbial products. Environ Health Perspect. 2014; 122:34-42. https://doi.org/10.1289/ehp.1307280.

18. Følsgaard NV, Schjørring S, Chawes BL, Rasmussen MA, Krogfelt KA, Brix S, Bisgaard H. Pathogenic bacteria colonizing the airways in asymptomatic neonates stimulates topical inflammatory mediator release. Am J Respir Crit Care Med. 2013; 187:589-95. https://doi.org/10.1164/ rccm.201207-12970C.

19. Essilfie AT, Simpson JL, Dunkley ML, Morgan LC, Oliver BG, Gibson PG, Foster PS, Hansbro PM. Combined Haemophilus influenzae respiratory infection and allergic airways disease drives chronic infection and features of neutrophilic asthma. Thorax. 2012; 67:588-99. https://doi. org/10.1136/thoraxjnl-2011-200160.

20. Simpson JL, Daly J, Baines KJ, Yang IA, Upham JW, Reynolds PN, Hodge S, James AL, Hugenholtz P, Willner D, Gibson PG. Airway dysbiosis: haemophilus influenzae and Tropheryma in poorly controlled asthma. Eur Respir J. 2016; 47:792-800. https://doi. org/10.1183/13993003.00405-2015.

21. Singh R, Mackay AJ, Patel AR, Garcha DS, Kowlessar BS, Brill SE, Donnelly LE, Barnes PJ, Donaldson GC, Wedzicha JA. Inflammatory thresholds and the speciesspecific effects of colonising bacteria in stable chronic obstructive pulmonary disease. Respir Res. 2014; 15:114. https://doi.org/10.1186/s12931-014-0114-1.
22. Hirota N, Martin JG. Mechanisms of airway remodeling. Chest. 2013; 144:1026-32. https://doi.org/10.1378/ chest.12-3073.

23. Zhao S, Jiang Y, Yang X, Guo D, Wang Y, Wang J, Wang R, Wang C. Lipopolysaccharides promote a shift from Th2derived airway eosinophilic inflammation to Th17-derived neutrophilic inflammation in an ovalbumin-sensitized murine asthma model. J Asthma. 2017; 54:447-55. https:// doi.org/10.1080/02770903.2016.1223687.

24. Al-Ramli W, Préfontaine D, Chouiali F, Martin JG, Olivenstein R, Lemière C, Hamid QT. (H)17-associated cytokines (IL-17A and IL-17F) in severe asthma. J Allergy Clin Immunol. 2009; 123:1185-87. https://doi. org/10.1016/j.jaci.2009.02.024.

25. Bullens DM, Truyen E, Coteur L, Dilissen E, Hellings PW, Dupont LJ, Ceuppens JL. IL-17 mRNA in sputum of asthmatic patients: linking $\mathrm{T}$ cell driven inflammation and granulocytic influx? Respir Res. 2006; 7:135. https://doi. org/10.1186/1465-9921-7-135.

26. Liu J, Feng Y, Yang K, Li Q, Ye L, Han L, Wan H. Early production of IL-17 protects against acute pulmonary Pseudomonas aeruginosa infection in mice. FEMS Immunol Med Microbiol. 2011; 61:179-88. https://doi. org/10.1111/j.1574-695X.2010.00764.x.

27. McKinley L, Alcorn JF, Peterson A, Dupont RB, Kapadia S, Logar A, Henry A, Irvin CG, Piganelli JD, Ray A, Kolls JK. TH17 cells mediate steroid-resistant airway inflammation and airway hyperresponsiveness in mice. J Immunol. 2008; 181:4089-97. https://doi.org/10.4049/jimmunol.181.6.4089.

28. Vazquez-Tello A, Semlali A, Chakir J, Martin JG, Leung DY, Eidelman DH, Hamid Q. Induction of glucocorticoid receptor-beta expression in epithelial cells of asthmatic airways by T-helper type 17 cytokines. Clin Exp Allergy. 2010; 40:1312-22. https://doi. org/10.1111/j.1365-2222.2010.03544.x.

29. Seroogy CM, Gern JE. The role of T regulatory cells in asthma. J Allergy Clin Immunol. 2005; 116:996-99. https:// doi.org/10.1016/j.jaci.2005.07.015.

30. Nabe T, Ikedo A, Hosokawa F, Kishima M, Fujii M, Mizutani N, Yoshino S, Ishihara K, Akiba S, Chaplin DD. Regulatory role of antigen-induced interleukin-10, produced by CD4(+) T cells, in airway neutrophilia in a murine model for asthma. Eur J Pharmacol. 2012; 677:154-62. https://doi. org/10.1016/j.ejphar.2011.12.020.

31. Bakr SI, Mahran MZ, Soliman DA. Role of regulatory CD4+CD25+ Foxp3 T cells in bronchial asthma in Egyptian children. Egypt J Immunol. 2013; 20:29-38.

32. Gauthier M, Chakraborty K, Oriss TB, Raundhal M, Das S, Chen J, Huff R, Sinha A, Fajt M, Ray P, Wenzel SE, Ray A. Severe asthma in humans and mouse model suggests a CXCL10 signature underlies corticosteroid-resistant Th1 bias. JCI Insight. 2017; 2:e94580. https://doi.org/10.1172/ jci.insight. 94580 . 
33. Eisenbarth SC, Piggott DA, Huleatt JW, Visintin I, Herrick CA, Bottomly K. Lipopolysaccharide-enhanced, toll-like receptor 4-dependent $\mathrm{T}$ helper cell type 2 responses to inhaled antigen. J Exp Med. 2002; 196:1645-51. https:// doi.org/10.1084/jem.20021340.

34. Simpson JL, Grissell TV, Douwes J, Scott RJ, Boyle MJ, Gibson PG. Innate immune activation in neutrophilic asthma and bronchiectasis. Thorax. 2007; 62:211-18. https://doi.org/10.1136/thx.2006.061358.

35. Liang Z, Zhang Q, Thomas CM, Chana KK, Gibeon D, Barnes PJ, Chung KF, Bhavsar PK, Donnelly LE. Impaired macrophage phagocytosis of bacteria in severe asthma. Respir Res. 2014; 15:72. https://doi. org/10.1186/1465-9921-15-72.

36. Simpson JL, Gibson PG, Yang IA, Upham J, James A, Reynolds PN, Hodge S, and AMAZES Study Research Group. Impaired macrophage phagocytosis in noneosinophilic asthma. Clin Exp Allergy. 2013; 43:29-35. https://doi.org/10.1111/j.1365-2222.2012.04075.x.

37. Fitzpatrick AM, Holguin F, Teague WG, Brown LA. Alveolar macrophage phagocytosis is impaired in children with poorly controlled asthma. J Allergy Clin Immunol. 2008; 121:1372-8, 1378.e1-3. https://doi.org/10.1016/j. jaci.2008.03.008.

38. Baines KJ, Simpson JL, Scott RJ, Gibson PG. Immune responses of airway neutrophils are impaired in asthma. Exp Lung Res. 2009; 35:554-69. https://doi. org/10.1080/01902140902777490.

39. da Silva-Martins CL, Couto SC, Muniz-Junqueira MI. Inhaled corticosteroid treatment for 6 months was not sufficient to normalize phagocytosis in asthmatic children. Clin Transl Allergy. 2013; 3:28. https://doi. org/10.1186/2045-7022-3-28.

40. Zetterlund A, Larsson PH, Müller-Suur C, Palmberg L, Larsson K. Budesonide but not terbutaline decreases phagocytosis in alveolar macrophages. Respir Med. 1998; 92:162-66. https://doi.org/10.1016/ S0954-6111(98)90089-0.

41. Roy MG, Livraghi-Butrico A, Fletcher AA, McElwee MM, Evans SE, Boerner RM, Alexander SN, Bellinghausen LK, Song AS, Petrova YM, Tuvim MJ, Adachi R, Romo I, et al. Muc 5 b is required for airway defence. Nature. 2014; 505:412-16. https://doi.org/10.1038/nature12807.

42. Marzoratti L, Iannella HA, Waterer GW. Inhaled corticosteroids and the increased risk of pneumonia. Ther Adv Respir Dis. 2013; 7:225-34. https://doi. org/10.1177/1753465813480550.

43. Venge $\mathrm{P}$. The eosinophil and airway remodelling in asthma. Clin Respir J. 2010 (Suppl 1); 4:15-19. https://doi. org/10.1111/j.1752-699X.2010.00192.x.

44. Pégorier S, Wagner LA, Gleich GJ, Pretolani M. Eosinophil-derived cationic proteins activate the synthesis of remodeling factors by airway epithelial cells. J Immunol. 2006; 177:4861-69. https://doi.org/10.4049/ jimmunol.177.7.4861.

45. Ciepiela O, Ostafin M, Demkow U. Neutrophils in asthma — a review. Respir Physiol Neurobiol. 2015; 209:1316. https://doi.org/10.1016/j.resp.2014.12.004.

46. Vargas A, Roux-Dalvai F, Droit A, Lavoie JP. Neutrophilderived exosomes: a new mechanism contributing to airway smooth muscle remodeling. Am J Respir Cell Mol Biol. 2016; 55:450-61. https://doi.org/10.1165/ rcmb.2016-0033OC.

47. van de Garde MD, Martinez FO, Melgert BN, Hylkema MN, Jonkers RE, Hamann J. Chronic exposure to glucocorticoids shapes gene expression and modulates innate and adaptive activation pathways in macrophages with distinct changes in leukocyte attraction. J Immunol. 2014; 192:1196-208. https://doi.org/10.4049/jimmunol.1302138. 